\title{
Effect of EDTA Root Conditioning on the Healing of Intrabony Defects Treated With an Enamel Matrix Protein Derivative
}

Anton Sculean, ${ }^{*}$ Mohammad Berakdar, ${ }^{\dagger}$ Britta Willershausen, ${ }^{\dagger}$ Nicole B. Arweiler, ${ }^{\ddagger}$ Jürgen Becker,, and Frank Schwarz $§$

Background: Regenerative periodontal therapy with an enamel matrix protein derivative (EMD) has been shown to promote regeneration in intrabony periodontal defects. However, in most clinical studies, root surface conditioning with EDTA was performed in conjunction with the application of EMD, and, therefore, it cannot be excluded that the results may also be attributable to the effect of the root conditioning procedure. The purpose of this study was to determine the effect of root conditioning on the healing of intrabony defects treated with EMD.

Methods: Twenty-four patients, each of whom exhibited one deep intrabony defect, were randomly treated with either open flap debridement (OFD) followed by root surface conditioning with EDTA and application of EMD (OFD + EDTA + EMD) or with OFD and application of EMD only (OFD + EMD). The following parameters were recorded at baseline and at 1 year: plaque index (PI), gingival index (GI), bleeding on probing (BOP), probing depth (PD), and clinical attachment level (CAL).

Results: No differences in any of the investigated parameters were observed at baseline between the two groups. Healing was uneventful in all patients. At 1 year after therapy, the OFD + EDTA + EMD group showed a reduction in mean PD from 9.3 $\pm 1.3 \mathrm{~mm}$ to $4.0 \pm 0.9 \mathrm{~mm}(P<0.001)$, and mean CAL changed from $10.8 \pm 2.2 \mathrm{~mm}$ to $7.1 \pm 2.8 \mathrm{~mm}(P<0.001)$. In the OFD + EMD group, mean PD was reduced from $9.3 \pm 1.2 \mathrm{~mm}$ to 4.2 $\pm 0.9 \mathrm{~mm}(P<0.001)$, and a change in mean CAL from $11.0 \pm$ $1.7 \mathrm{~mm}$ to $7.3 \pm 1.6 \mathrm{~mm}(P<0.001)$. There were no significant differences in any of the investigated parameters between the two groups.

Conclusion: In intrabony defects, regenerative surgery including OFD + EDTA + EMD failed to show statistically significant differences in terms of PD reduction and CAL gain compared to treatment with OFD + EMD. J Periodontol 2006;77:11671172.

\section{KEY WORDS}

Clinical study; EDTA; enamel matrix proteins; root surface conditioning.

\footnotetext{
* Department of Periodontology, Radboud University Medical Center, Nijmegen, The Netherlands.

$\dagger$ Department of Conservative Dentistry and Periodontology, Johannes Gutenberg

University, Mainz, Germany.

‡ Department of Operative Dentistry and Periodontology, Albrecht-Ludwigs University, Freiburg, Germany.

$\S$ Department of Oral Surgery, Heinrich Heine University, Düsseldorf, Germany.
}

$\mathrm{R}$ econstructive periodontal surgery with an enamel matrix protein derivative (EMD) has been shown to promote periodontal regeneration (i.e., formation of new cementum, new periodontal ligament, and new bone) in animals and humans. ${ }^{1-13}$ Clinically, treatment of intrabony defects by means of open flap debridement (OFD) and application of EMD resulted in greater probing depth (PD) reduction and clinical attachment level (CAL) gain than OFD alone. ${ }^{14-21}$ The application of EMD was usually performed following root surface conditioning with phosphoric acid, citric acid, or EDTA. ${ }^{18-21}$ In those clinical trials, the most frequently employed root conditioning agent was $24 \%$ EDTA. ${ }^{15-21}$ The biologic rationale of using EDTA for root surface conditioning is based on findings from experimental studies indicating that EDTA operating at neutral $\mathrm{pH}$ appeared to effectively remove the smear layer produced by scaling and root planing and to selectively remove mineral from the dentin or cementum surface exposing a collagenous matrix. ${ }^{22-25}$ In contrast, etching with citric and phosphoric acids appeared to remove not only the mineral component but also the collagenous matrix. ${ }^{22-25}$ Furthermore, it has been demonstrated that a dentin or cementum surface in which collagen had been exposed by EDTA etching appeared to produce a more biocompatible surface

doi: $10.1902 /$ jop.2006.050300 
compared to etching at low $\mathrm{pH}$, whereas low $\mathrm{pH}$ etching agents exerted an immediate necrotizing effect on vital periodontal tissues in contrast to EDTA. ${ }^{22,25-28}$ Although results from controlled clinical studies have failed to demonstrate a significant clinical benefit when root conditioning using EDTA gel was employed as an adjunct to surgical therapy, it cannot be excluded that the treatment outcome reported following regenerative periodontal surgery with EMD may also be attributable to the effect of the root conditioning procedure. ${ }^{29,30}$ However, there are still limited data from controlled clinical studies evaluating the influence of a root conditioning procedure with EDTA on the clinical results following regenerative periodontal surgery with EMD.

Therefore, the aim of the present randomized, controlled, blinded, clinical trial was to determine the effect of EDTA root conditioning on the healing of intrabony defects treated with EMD.

\section{MATERIALS AND METHODS}

A total of 24 patients ( 14 females and 10 males; mean age: $41 \pm 11.5$ years) with chronic, generalized, advanced periodontitis were included in this prospective, randomized, controlled, blinded, parallel design study (i.e., 12 patients in each group) after having signed an informed consent form. Each patient participated in the study with one intrabony periodontal defect. The study was performed according to the Declaration of Helsinki as revised in 1983. The criteria needed for inclusion in the study were as follows: 1) no systemic diseases that could influence the outcome of the therapy; 2) a good level of oral hygiene, defined as a whole mouth plaque index $(\mathrm{PI})<1 ; 313$ ) compliance with the maintenance program; 4) presence of one intrabony defect with a PD $\geq 6 \mathrm{~mm}$; and 5) an intrabony component $\geq 3 \mathrm{~mm}$ as detected on the radiographs. All patients received non-surgical periodontal treatment, including oral hygiene instructions and scaling and root planing under local anesthesia at least 3 months prior to the start of the study.

The following clinical parameters were assessed by the same examiner (MB) 1 week prior and 1 year after the surgical procedure using the same periodontal probe:l $\mathrm{PI}$, gingival index $(\mathrm{GI}),{ }^{31}$ bleeding on probing (BOP), PD, gingival recession (GR), and CAL. Measurements were made at six sites per tooth: mesiovestibular (mv), mid-vestibular (v), disto-vestibular (dv), mesio-oral (ml), mid-oral (l), and disto-oral (dl). The cemento-enamel junction (CEJ) was used as the reference point. In cases where the CEJ was not visible, a restoration margin was used for these measurements. The study reports only measurements at the same deepest point of the selected defect. Preand postoperative radiographs were taken with the long-cone paralleling technique.

\section{Intraexaminer Reproducibility}

Five patients, each showing 10 teeth (single and multirooted) with probing depths $>6 \mathrm{~mm}$ on at least one aspect of each tooth, were used to calibrate the examiner. The examiner evaluated the patients on two separate occasions, 48 hours apart. Calibration was accepted if measurements at baseline and at 48 hours were similar to the millimeter at $>90 \%$ level. The examiner was not aware of the surgical procedure to be performed.

\section{Surgical Procedure}

All operative procedures were performed by the same surgeon (AS). Following local anesthesia and placement of intracrevicular incisions, mucoperiosteal flaps were raised vestibularly and orally. Vertical releasing incisions were performed only if necessary for a better access or to achieve a better closure of the surgical site. All granulation tissue was removed from the defects, and the roots were thoroughly scaled and planed using hand and ultrasonic instruments. During surgery, the following measurements were made: 1) the distance from the CEJ to the bottom of the defect (CEJ-BD); and 2) the distance from the $\mathrm{CEJ}$ to the most coronal extension of the alveolar bone crest (CEJ-BC). The intrabony component (INTRA) of the defects was defined as CEJ-BD - CEJ-BC.

The defects were randomly assigned before surgery to the two treatment groups with the randomized block approach. Blocking to control for the effects of the prognostic variables INTRA and CAL was used to decrease outcome variability. ${ }^{32}$ For allowing randomization, INTRA was estimated before surgery on radiographs and by performing transgingival bone sounding.

In the OFD + EDTA + EMD group, the root surfaces adjacent to the defects were conditioned for 2 minutes with $24 \%$ EDTA gel ( $\mathrm{pH} 6.7)^{\text {Il }}$ according to the instructions given by the manufacturer. The defects, the root surfaces, and the adjacent mucoperiosteal flaps were then thoroughly rinsed with sterile saline to remove EDTA remnants. Following root conditioning, EMD\# was applied on the root surfaces and into the defects. In the OFD + EMD group, EMD was applied on the root surface directly after completing root scaling and planing and copious rinsing of the wound. In all cases, primary wound closure was achieved by means of vertical and horizontal mattress sutures.

\section{Postoperative Care}

The postoperative care consisted of $0.2 \%$ chlorhexidine rinses twice a day for 4 weeks. The sutures were removed 14 days after the surgery. Recall appointments were scheduled every second week during

UNC 15, Hu-Friedy, Chicago, IL.

II PrefGel, Straumann, Basel, Switzerland.

\# Emdogain, Straumann. 
the first 2 months after surgery and monthly following the rest of the observation period of 1 year. Neither probing nor subgingival instrumentation were performed during the first year after surgery.

\section{Statistical Analysis}

The statistical analysis was performed using a commercially available software program. ** The primary outcome variable was the CAL. In the calculations, the deepest site per tooth was included. For the statistical evaluation of the changes from baseline to 1 year, the paired $t$ test was used (two-tailed $t$ test). For the comparisons between the groups, the unpaired $t$ test was used (two-tailed $t$ test). The $\alpha$ error was set at 0.05 . The power of the study, given $1 \mathrm{~mm}$ as a significant difference between the groups, was calculated to be 0.70 .

\section{RESULTS}

The postoperative healing was considered generally uneventful. Minor complications were related to usual postoperative swelling and occurred within the first days after surgery. Neither allergic reactions nor suppuration or abscesses were observed in any of the patients.

The mean PI, GI, and BOP at the treated sites for each of the two groups at baseline and after 1 year are summarized in Table 1. The mean PI did not reveal a statistically significant difference in any of the two groups compared to baseline or between the groups. In both groups, the GI and BOP improved significantly compared to baseline $(P<0.001)$. However, at 1 year, the difference between the groups was not statistically significant.

Defect characteristics with respect to tooth type are presented in Table 2. No differences in the distribution of the defects were found between the two groups.

Baseline defect characteristics are presented in Table 3. At baseline, no differences in the depth of the intrabony component were found between the two groups.

The clinical results at 1 year after treatment are presented in Table 4. No differences in any of the investigated parameters were observed at baseline between the two groups. Healing was uneventful in all patients. At 1 year after therapy, the OFD + EDTA + EMD group showed a reduction in mean PD from $9.3 \pm 1.3 \mathrm{~mm}$ to $4.0 \pm 0.9 \mathrm{~mm}(P<0.001)$ and a change in mean CAL from $10.8 \pm 2.2 \mathrm{~mm}$ to $7.1 \pm 2.8 \mathrm{~mm}$ $(P<0.001)$. In the OFD + EMD group, mean PD was reduced from $9.3 \pm 1.2 \mathrm{~mm}$ to $4.2 \pm 0.9 \mathrm{~mm}$ $(P<0.001)$, and the mean CAL changed from $11.0 \pm$ $1.7 \mathrm{~mm}$ to $7.3 \pm 1.6 \mathrm{~mm}(P<0.001)$. There were no significant differences in terms of PD reduction and CAL gain between the two groups.

The frequency distribution of CAL gain for both treatment groups is shown in Table 5. In both groups,
Table I.

Plaque, Gingival, and Bleeding Scores at the Treated Sites at Baseline and the 1 -Year Examination (mean \pm SD)

\begin{tabular}{lcc}
\hline & $\begin{array}{c}\text { OFD + EDTA } \\
+ \text { EMD }(\mathrm{N}=12)\end{array}$ & $\begin{array}{c}\text { OFD + EMD } \\
(\mathrm{N}=12)\end{array}$ \\
\hline $\begin{array}{l}\text { Plaque index scores } \\
\text { Baseline } \\
12 \text { months }\end{array}$ & $0.7 \pm 0.3$ & $0.7 \pm 0.2$ \\
Gingival index scores & $0.7 \pm 0.2$ & $0.6 \pm 0.4$ \\
Baseline & & \\
12 months & $1.4 \pm 0.6$ & $1.5 \pm 0.6$ \\
Bleeding scores & $0.6 \pm 0.4$ & $0.7 \pm 0.4$ \\
Baseline & & \\
12 months & $39 \%$ & $37 \%$ \\
\hline
\end{tabular}

\section{Table 2.}

\section{Distribution and Configuration of Treated Defects}

\begin{tabular}{lcc}
\hline & $\begin{array}{c}\text { OFD + EDTA } \\
+ \text { EMD }(\mathrm{N}=12)\end{array}$ & $\begin{array}{c}\text { OFD + EMD } \\
(\mathrm{N}=12)\end{array}$ \\
\hline Maxilla & 5 & 6 \\
Mandible & 7 & 6 \\
Anterior teeth & 5 & 4 \\
Premolars & 4 & 5 \\
Molars & 3 & 3 \\
1- to 2-wall & 1 & 2 \\
2-wall & 9 & 8 \\
3-wall & 2 & 2 \\
\hline
\end{tabular}

all sites (100\%) gained $\geq 2 \mathrm{~mm}$ CAL. A CAL gain $\geq 3 \mathrm{~mm}$ was measured at 11 sites (92\%) in each of the two groups. Patients who reported smoking only occasionally were not considered smokers. ${ }^{33}$ According to the given definition, there were no smokers included in the present study.

\section{DISCUSSION}

The results of the present study have shown that treatment of intrabony periodontal defects by means of OFD and application of EMD with or without root surface conditioning with EDTA resulted in significant PD reductions and CAL gains. No statistically significant

* * SPSS for Windows, SPSS, Chicago, IL. 
Table 3.

Baseline Defect Characteristics (mean \pm SD, mm)

\begin{tabular}{lcccccc}
\hline Treatment & PD & GR & CAL & CEJ-BD & CEJ-BC & INTRA \\
\hline OFD + EDTA + EMD (N=12) & $9.3 \pm 1.3$ & $1.5 \pm 1.8$ & $10.8 \pm 2.2$ & $11.6 \pm 1.8$ & $7.4 \pm 1.7$ & $4.2 \pm 1.7$ \\
OFD + EMD (N = 12) & $9.3 \pm 1.2$ & $1.8 \pm 1.0$ & $11.0 \pm 1.7$ & $11.7 \pm 1.5$ & $7.6 \pm 1.6$ & $4.1 \pm 1.5$ \\
\hline
\end{tabular}

Table 4.

\section{Clinical Parameters at Baseline and 1 Year for Test and Control Groups*}

\begin{tabular}{lcccc}
\hline & Baseline & I Year & Difference & Significance \\
\hline PD & & & & \\
OFD + EDTA + EMD & $9.3 \pm 1.3$ & $4.0 \pm 0.9$ & $5.3 \pm 1.1$ & $P<0.001$ \\
OFD + EMD & $9.3 \pm 1.2$ & $4.2 \pm 0.9$ & $5.1 \pm 0.8$ & $P<0.001$ \\
& & & NS & \\
GR & & & & \\
OFD + EDTA + EMD & $1.5 \pm 1.8$ & $3.0 \pm 2.2$ & $1.5 \pm 1.0$ & $P<0.01$ \\
OFD + EMD & $1.8 \pm 1.0$ & $3.2 \pm 1.3$ & $1.3 \pm 0.6$ & $P<0.01$ \\
& & & $N S$ & \\
CAL & & & & \\
OFD + EDTA + EMD & $10.8 \pm 2.2$ & $7.1 \pm 2.8$ & $3.8 \pm 1.1$ & $P<0.001$ \\
OFD + EMD & $11.0 \pm 1.7$ & $7.3 \pm 1.6$ & $3.7 \pm 0.7$ & $P<0.001$ \\
& & & NS & \\
\hline
\end{tabular}

NS $=$ not statistically significant

* $N=12$ for each group.

differences between the two treatment modalities in any of the investigated clinical parameters were found at 1 year after therapy. However, it should be emphasized that the study does not have the statistical power to rule out the possibility of a difference between the two groups. Further studies, with a much higher number of patients and defects, would be needed to detect an eventual difference between the treatments. ${ }^{34}$ Moreover, it cannot be excluded that the inclusion of a third group receiving only surgical debridement might have added additional information to the study. The fact that postoperative discomforts such as swelling and pain were minimal in all treated patients also indicates that neither the application of EMD alone nor the combination of EDTA + EMD seems to interfere with the healing process. These findings are in agreement with the results from previous human histologic and clinical studies that failed to show serious postoperative complications following the use of EMD, EDTA, or both in conjunction with surgical periodontal therapy. ${ }^{7-21,26,28,35,36}$

The results obtained in the OFD + EDTA + EMD group are in agreement with previously published data using a comparable surgical protocol. ${ }^{15-21,36}$ However, it needs to be pointed out that treatment with OFD + EMD in the present study resulted in comparable PD reductions and CAL gains to treatment with OFD + EDTA + EMD. The results obtained with OFD + EMD are comparable to those from a case report study evaluating the healing of 15 consecutive patients with a total of 25 intrabony defects treated according to a similar protocol. ${ }^{35}$ In that study, neither etching nor chemical preparation of the root surfaces was carried out. At 12 months, the results demonstrated a mean PD reduction of $4.4 \pm 1.3 \mathrm{~mm}$ and a mean CAL gain of $3.6 \pm 1.2$ $\mathrm{mm}$. A total of 14 sites demonstrated a CAL gain of 2 to $3 \mathrm{~mm}$, nine sites demonstrated a gain of 4 to $5 \mathrm{~mm}$, and two sites demonstrated a gain of $6 \mathrm{~mm}$. Our findings are also in line with those of a very recent practice-based clinical and radiographic study that failed to demonstrate any significant benefit of EDTA root conditioning as an adjunct to regenerative surgery with EMD in intrabony defects. ${ }^{36}$

The choice of EDTA for root surface conditioning was based on results of previous histologic studies in animals that provided evidence that application of EDTA significantly enhances periodontal wound healing compared to other conditioning agents such as phosphoric acid or citric acid. ${ }^{26-28}$ Following application of EDTA, it was also shown that the migration of PDL fibroblasts toward the root surface is significantly enhanced compared to the control (no root conditioning) sites or the other conditioning agents used. ${ }^{28}$ On the other hand, previous results from controlled clinical studies evaluating the effects of root conditioning using EDTA gel as an adjunct to surgical therapy for the treatment of intraosseous periodontal defects have failed to show statistically significant differences in the treatment outcome between the groups treated with OFD + EDTA or OFD alone. ${ }^{29,30}$ In a controlled clinical study comparing the treatment 
Table 5.

\section{Frequency Distribution of CAL Gain in the Two Groups*}

\begin{tabular}{lcccc}
\hline \multirow{2}{*}{ CAL } & \multicolumn{2}{c}{ OFD + EDTA + EMD } & \multicolumn{2}{c}{ OFD + EMD } \\
\cline { 2 - 5 } Gain $(\mathrm{mm})$ & $\mathrm{N}$ & $\%$ & $\mathrm{~N}$ & $\%$ \\
\hline 0 & 0 & 0 & 0 & 0 \\
1 & 0 & 0 & 0 & 0 \\
2 & 1 & 8 & 1 & 8 \\
3 & 5 & 42 & 3 & 26 \\
4 & 1 & 8 & 7 & 58 \\
5 & 5 & 42 & 1 & 8 \\
\hline
\end{tabular}

$* N=12$ for each group.

outcome following root surface conditioning using an EDTA gel preparation in conjunction with surgical therapy with that following conventional flap surgery in periodontal intraosseous defects, mean CAL gain was $1.8 \pm 1.5 \mathrm{~mm}$ in the EDTA group and $1.0 \pm 1.7$ $\mathrm{mm}$ in the control group, respectively. ${ }^{29}$ There were no statistically significant differences between the two groups. Comparable findings were also reported from a controlled clinical trial assessing the effects of an EDTA gel applied during surgical periodontal therapy on PD reduction and CAL gain. ${ }^{30}$ In that study, periodontal surgery was performed in conjunction with either root surface conditioning with citric acid, EDTA, or alone (control). No statistically significant differences were found between the three groups in terms of PD reduction and CAL gain at 3 and 6 months following therapy.

In the present study, the fact that similar PD reductions and CAL gains were obtained in both groups indicates that the clinical results may be attributed to the effect of EMD rather than to the root surface conditioning itself. These findings also question the clinical relevance of EDTA root conditioning in conjunction with regenerative periodontal surgery with EMD.

\section{CONCLUSION}

Within their limits, the present results have failed to show statistically significant differences in terms of $P D$ reduction and CAL gain following regenerative surgery with either OFD + EDTA + EMD or OFD + EMD.

\section{REFERENCES}

1. Hammarström L, Heijl L, Gestrelius S. Periodontal regeneration in a buccal dehiscence model in monkeys after application of enamel matrix proteins. J Clin Periodontol 1997;24:669-677.
2. Sculean A, Donos N, Reich E, Brecx M, Karring T. Healing of recession-type defects following treatment with enamel matrix proteins or guided tissue regeneration. A pilot study in monkeys. J Parodontol Implantol Orale 2000;19:19-31.

3. Sculean A, Donos N, Brecx M, Reich E, Karring T. Treatment of intrabony defects with enamel matrix proteins and guided tissue regeneration. An experimental study in monkeys. J Clin Periodontol 2000; 27:466-472.

4. Donos N, Sculean A, Glavind L, Reich E, Karring T. Wound healing of degree III furcation involvements following guided tissue regeneration and/or Emdogain. A histologic study. J Clin Periodontol 2003;30: $1061-1068$.

5. Cochran DL, King GN, Schoolfield J, Velasquez-Plata D, Mellonig JT, Jones A. The effect of enamel matrix proteins on periodontal regeneration as determined by histologic analyses. J Periodontol 2003;74:10431055.

6. Sallum EA, Pimentel SP, Saldanha JB, et al. Enamel matrix derivative and guided tissue regeneration in the treatment of dehiscence-type defects: A histomorphometric study in dogs. J Periodontol 2004;75:13571363.

7. Heijl L. Periodontal regeneration with enamel matrix derivative in one human experimental defect. A case report. J Clin Periodontol 1997;24:693-696.

8. Mellonig JT. Enamel matrix derivative for periodontal reconstructive surgery: Technique and clinical and histologic case report. Int $J$ Periodontics Restorative Dent 1999;19:8-19.

9. Yukna RA, Mellonig J. Histologic evaluation of periodontal healing in humans following regenerative therapy with enamel matrix derivative. A 10-case series. $J$ Periodontol 2000;71:752-759.

10. Sculean A, Donos N, Windisch P, et al. Healing of human intrabony defects following treatment with enamel matrix proteins or guided tissue regeneration. $J$ Periodontal Res 1999;34:310-322.

11. Sculean A, Chiantella GC, Windisch P, Donos N. Clinical and histologic evaluation of treatment of intrabony defects with an enamel matrix protein derivative (Emdogain). Int J Periodontics Restorative Dent 2000; 20:374-381.

12. McGuire MK, Cochran DL. Evaluation of human recession defects treated with coronally advanced flaps and either enamel matrix derivative or connective tissue. Part 2: Histological evaluation. J Periodontol 2003;74:1126-1135.

13. Majzoub Z, Bobbo M, Atiyeh F, Cordioli G. Two patterns of histologic healing in an intrabony defect following treatment with enamel matrix derivative: A human case report. Int $J$ Periodontics Restorative Dent 2005;25:283-294.

14. Heijl L, Heden G, Svardström G, Ostgren A. Enamel matrix derivative (Emdogain) in the treatment of intrabony periodontal defects. J Clin Periodontol 1997;24:705-714.

15. Okuda K, Momose M, Miyazaki A, Miyazaki A. Enamel matrix derivative in the treatment of human intrabony osseous defects. J Periodontol 2000;71:1821-1828.

16. Pontoriero R, Wennström J, Lindhe J. The use of barrier membranes and enamel matrix proteins in the treatment of angular bone defects. A prospective controlled clinical study. J Clin Periodontol 1999;26: 833-840. 
17. Silvestri M, Ricci G, Rasperini G, Sartori S, Cattaneo V. Comparison of treatments of intrabony defects with enamel matrix derivative, guided tissue regeneration with a nonresorbable membrane and Widman modified flap. A pilot study. J Clin Periodontol 2000;27: 603-610.

18. Froum SJ, Weinberg MA, Rosenberg E, Tarnow D. A comparative study utilizing open flap debridement with and without enamel matrix derivative in the treatment of periodontal intrabony defects: A 12-month re-entry study. J Periodontol 2001;72: 25-34.

19. Sculean A, Windisch P, Chiantella GC, Donos N, Brecx M, Reich E. Treatment of intrabony defects with enamel matrix proteins and guided tissue regeneration. A prospective controlled clinical study. J Clin Periodontol 2001;28:397-403.

20. Zucchelli G, Bernardi F, Montebugnoli L, De SM. Enamel matrix proteins and guided tissue regeneration with titanium-reinforced expanded polytetrafluoroethylene membranes in the treatment of intrabony defects: A comparative controlled clinical trial. J Periodontol 2002;73:3-12.

21. Tonetti MS, Lang NP, Cortellini P, et al. Enamel matrix proteins in the regenerative therapy of deep intrabony defects. A multicentre randomized controlled clinical trial. J Clin Periodontol 2002;29: 317-325.

22. Blomlöf J, Lindskog S. Root surface texture and early cell and tissue colonization after different etching modalities. Eur J Oral Sci 1995;103:17-24.

23. Blomlöf J, Blomlöf L, Lindskog S. Effect of different concentrations of EDTA on smear removal and collagen exposure in periodontitis-effected root surfaces. $J$ Clin Periodontol 1997;24:534-537.

24. Blomlöf JPS, Blomlöf LB, Lindskog SF. Smear layer formed by different root planing modalities and its removal by an ethylenediaminetetraacetic acid gel preparation. Int J Periodontics Restorative Dent 1997; 17:242-249.

25. Blomlöf J. Root cementum appearance in healthy monkeys and periodontitis-prone patients after different etching modalities. J Clin Periodontol 1996;23: 12-18.
26. Blomlöf J, Lindskog S. Periodontal tissue vitality after different etching modalities. J Clin Periodontol 1995; 22:464-468.

27. Blomlöf J, Jansson L, Blomlöf L, Lindskog S. Longtime etching at low $\mathrm{pH}$ jeopardizes periodontal healing. J Clin Periodontol 1995;22:459-463.

28. Blomlöf J, Jansson L, Blomlöf L, Lindskog S. Root surface etching at neutral $\mathrm{pH}$ promotes periodontal healing. J Clin Periodontol 1996;23:50-55.

29. Mayfield L, Söderholm G, Norderyd O, Attström R. Root conditioning using EDTA gel as adjunct to surgical therapy for the treatment of intraosseous periodontal defects. J Clin Periodontol 1998;25:707-714.

30. Blomlöf L, Jonsson B, Blomlöf J, Lindskog S. A clinical study of root surface conditioning with an EDTA gel. II. Surgical periodontal treatment. Int J Periodontics Restorative Dent 2000;20:566-573.

31. Löe H. The Gingival Index, the Plaque Index and the Retention Index system. J Periodontol 1967;38:610-616.

32. Fleiss J. The Design and Analysis of Clinical Experiments. New York: John Wiley E Sons; 1986:120-148.

33. Tonetti MS, Pini Prato GP, Cortellini P. Effect of cigarette smoking on periodontal health following GTR in infrabony defects. A preliminary retrospective study. $J$ Clin Periodontol 1995;22:229-234.

34. Gunsolley JC, Elswick RK, Davenport JM. Equivalence and superiority testing in regeneration clinical trials. J Periodontol 1998;69:521-527.

35. Parashis A, Tsiklakis K. Clinical and radiographic findings following application of enamel matrix derivative in the treatment of intrabony defects. A series of case reports. J Clin Periodontol 2000;27:705-713.

36. Parashis AO, Konstantinos T, Tatakis DN. EDTA gel root conditioning: Lack of effect on clinical and radiographic outcomes of intrabony defect treatment with enamel matrix derivative. J Periodontol 2006;77:103-110.

Correspondence: Dr. Anton Sculean, Department of Periodontology, Radboud University Medical Center, P.O. Box 9101, Internal Postal Code 117, 6500 Nijmegen, Philips van Leydenlaan 25, The Netherlands. Fax: 31-24-361-46-57; e-mail: a.sculean@dent.umcn.nl.

Accepted for publication February 1, 2006. 